\title{
Phase II Study of Carboplatin and Pemetrexed Followed by Gefitinib for Patients with Advanced Non-Small Cell Lung Cancer Harboring Sensitive EGFR Mutation
}

\author{
Saki Manabe1, Fumihiro Oshita1,2*, Shuji Murakami', Tetsuro Kondo', Haruhiro Saito1, \\ Takeshi Kaneko 3 , Kouzo Yamada ${ }^{1}$ \\ ${ }^{1}$ Department of Thoracic Oncology, Kanagawa Cancer Center, Yokohama, Japan \\ ${ }^{2}$ Department of General Medicine, Kanagawa Prefectural Ashigarakami-Hospital, Matsuda, Japan \\ ${ }^{3}$ Department of Pulmonology, Yokohama City University Graduate School of Medicine, Yokohama, Japan \\ Email: *foshita@ashigarakami-hospital.jp
}

Received 28 October 2015; accepted 11 December 2015; published 14 December 2015

Copyright (C) 2015 by authors and Scientific Research Publishing Inc.

This work is licensed under the Creative Commons Attribution International License (CC BY). http://creativecommons.org/licenses/by/4.0/

(c) $\underset{\mathrm{EY}}{\mathrm{Br}}$ Open Access

\section{Abstract}

We conducted a phase II study of combination chemotherapy with carboplatin (Cb) and pemetrexed (Pem) followed by gefitinib (Gef) to determine the effects and toxicities in patients with non-small cell lung cancer (NSCLC) harboring sensitive EGFR mutation. Eligible patients received four courses of $\mathrm{Cb}$ at a dose corresponding to a target area under the curve equal to $6 \mathrm{mg} / \mathrm{mL} \cdot \mathrm{min}$ and $500 \mathrm{mg} / \mathrm{m}^{2}$ Pem on day 1 every three to four weeks followed by sequential Gef $250 \mathrm{mg}$ once a day until tumor progression. Sixteen of registered 28 patients responded to $\mathrm{Cb}$ and $\mathrm{Pem}$ combination. Twenty-seven patients received sequential Gef and 8 non-responders to $\mathrm{Cb}$ and $\mathrm{Pem}$ achieved PR. The overall response rate was $85.7 \%$. Among the major toxicities, grade 3 SGPT elevation, nausea and thrombosis were observed in 3,3 and 1 patients, respectively, who received $\mathrm{Cb}$ and Pem, and grade 3 SGPT elevation and dry skin were observed in 5 and 1 patients, respectively, who received Gef. There was no febrile neutropenia and no treatment-related death. The median progression-free survival time was 19.1 months. Among 21 patients who were followed up for more than 2 years, 14 survived during that time. $\mathrm{Cb}$ and Pem followed by Gef maintenance are recommended for further evaluation for patients with metastatic NSCLC harboring sensitive EGFR mutation.

${ }^{*}$ Corresponding author.

How to cite this paper: Manabe, S., Oshita, F., Murakami, S., Kondo, T., Saito, H., Kaneko, T. and Yamada, K. (2015) Phase II Study of Carboplatin and Pemetrexed Followed by Gefitinib for Patients with Advanced Non-Small Cell Lung Cancer Harboring Sensitive EGFR Mutation. Journal of Cancer Therapy, 6, 1214-1222. http://dx.doi.org/10.4236/jct.2015.615132 


\section{Keywords}

\section{Pemetrexed, Gefitinib, EGFR Mutation, Non-Small Cell Lung Cancer, Chemotherapy}

\section{Introduction}

Current chemotherapy regimens for metastatic non-small cell lung cancer (NSCLC) such as adenocarcinoma, squamous cell carcinoma, large cell carcinoma and undifferentiated carcinoma are not particularly effective. Regimens based on combinations of anticancer agents such as vinorelbine, gemcitabine, docetaxel and paclitaxel with platinum compounds have emerged as a gold standard for such patients [1]. Additional improvement of overall survival has been demonstrated for bevacizumab with carboplatin plus paclitaxel for patients with advanced or recurrent NSCLC [2]. The epidermal growth factor receptor (EGFR) superfamily was identified early as a potential therapeutic target in solid tumors. Inhibitors of EGFR tyrosine kinase such as gefitinib (Gef) are orally active and can produce an objective response in patients with previously treated or untreated advanced NSCLC [3]-[5]. Two pivotal studies demonstrated that EGFR mutants enhanced tyrosine kinase activity in response to epidermal growth factor and increased sensitivity to inhibition by Gef, and have shown that the presence of EGFR mutant is strongly correlated with an increased response to EGFR tyrosine kinase inhibitors (TKI) in patients with NSCLC [6] [7]. Large randomized controlled trials involving patient cohorts enriched for patients harboring EGFR-activating mutations have demonstrated the superiority of EGFR-TKI treatment over conventional cytotoxic drugs in terms of progression-free survival and objective response rate [8]-[12]. Two studies designed to compare the activity of Gef with that of platinum-based chemotherapy in Japan demonstrated significantly better progression-free survival in the Gef treatment group [9] [10]. All of the patients in both studies were eligible for crossover treatment with platinum-based chemotherapy and Gef. Most patients who had received platinum-based first-line chemotherapy chose Gef for the second-line treatment, and achieved tumor regression with the latter agent. Thus, long-term analysis has demonstrated that courses of treatment initiated with Gef achieve overall survival similar to that of traditional treatment initiated with platinum doublet regimens for such patients [9] [10]. Accordingly, it has been suggested that patients with EGFR mutations should receive both Gef and a platinum doublet regimen. However, in the two trials conducted in Japan, one third to half of patients who received Gef as first-line therapy continued to receive Gef beyond the PD stage because of anxiety about chemotherapy-related cytotoxicity. It is important to choose a treatment strategy that is acceptable for the majority of patients, and for this purpose, less toxic platinum-based regimens might be selected. Most cases of EGFR mutation are detected in non-squamous cell carcinoma, and drugs that are more effective against this histologic type of cancer should be chosen. Pemetrexed (Pem) is the first drug for which effects have been found to differ according to histologic type [13], being more effective against non-squamous than against squamous cell carcinoma. There are no significant differences between cisplatin-based and carboplatin (Cb)-based regimens [14] [15], and Cb plus Pem has been shown to have almost the same efficacy as Cb plus gemcitabine, but with lower toxicity [16]. Therefore, we planned a prospective phase II study of Cb and Pem followed by sequential Gef therapy.

\section{Patients and Methods}

Patients. Patients with histologically or cytologically proven stage IIIB or IV NSCLC harboring sensitive EGFR mutations were registered for the $\mathrm{Cb}$ and Pem combination followed by Gef chemotherapy. Eligibility criteria for the chemotherapy were: no prior chemotherapy, expected survival of at least six weeks, age 20 to 75 years, Eastern Cooperative Oncology Group PS score $\leq 1$, leukocyte count $\geq 4000 / \mu 1$, hemoglobin count $\geq 9.0 \mathrm{~g} / \mathrm{dl}$, platelet count $\geq 100,000 / \mu 1$, total serum bilirubin $\leq 1.5 \mathrm{mg} / \mathrm{dl}$, aspartate aminotransferase and alanine aminotransferase $\leq 100 \mathrm{IU} / \mathrm{L}$, and serum creatinine $\leq 1.5 \mathrm{mg} / \mathrm{dl}$. Patients with postoperative recurrence were eligible. The Institutional Review Board of Kanagawa Cancer Center reviewed and approved this study prior to commencement. Written informed consent was obtained in every case.

Chemotherapy. Patients exhibiting no disease progression were treated every 3 to 4 weeks with $\mathrm{Cb}$ at a dose corresponding to a target area under the curve (AUC) equal to $6 \mathrm{mg} / \mathrm{mL} \cdot \mathrm{min}$ (AUC 6) and $500 \mathrm{mg} / \mathrm{m}^{2}$ Pem on day 1 . All patients were instructed to take oral daily doses of folic acid beginning 1 week before the first dose of 
Pem and 3 weeks after the last cycle of CbPem. Injection of vitamin B12 was given 1 week before the first dose of Pem and at 9-week intervals during CbPem treatment. Patients received 5- $\mathrm{HT}_{3}$ antagonist IV and $8 \mathrm{mg}$ dexamethasone IV before administration of the anticancer drugs. The $\mathrm{Cb}$ and Pem chemotherapy was repeated for a maximum of four cycles unless the disease progressed, or if severe toxicities developed. Patients who required dose reduction twice terminated $\mathrm{Cb}$ and Pem chemotherapy and switched to sequential chemotherapy with Gef. Non-responders after 2 cycles of CbPem were allowed to switch to Gef treatment.

Sequential chemotherapy with Gef $250 \mathrm{mg}$ p.o. once a day was started after completion of the $\mathrm{Cb}$ and Pem combination chemotherapy when the following criteria were satisfied: PS score $\leq 2$, leukocyte count $\geq 3000 / \mu$, platelet count $\geq 100,000 / \mu 1$, total serum bilirubin $\leq 1.5 \mathrm{mg} / \mathrm{dl}$, aspartate aminotransferase and alanine aminotransferase $\leq 100 \mathrm{IU} / \mathrm{L}$, serum creatinine $\leq 1.5 \mathrm{mg} / \mathrm{dl}$, and other toxicities $\leq$ grade 1 . If grade 4 hematological toxicities, grade 2 pneumonitis, or grade 3 other non-hematological toxicities appeared, sequential Gef treatment was interrupted for a maximum of 30 days until the toxicities became less than grade 2. Tumor responses were evaluated according to the RECIST criteria [17], and toxicities were evaluated according to the NCI-CTC ver.3 criteria.

Study design. We chose a $60 \%$ two-year survival rate as a desirable target level, and considered a $40 \%$ response rate to be non-significant. The study design had the power to detect responses greater than $90 \%$, with less than $10 \%$ error. Therefore, we required 29 assessable patients in the first stage and 25 in the second stage, according to the Minimax design of Simon [18]. We decided to stop the study if fewer than 12 patients survived for 2 years in the first stage. This regimen was defined as active if the number of 2-year survivors was $\geq 28$ out of 54 patients, and inactive if the number of responders was $\leq 27$. Survival was estimated using the method of Kaplan and Meier. This study is registered with the University Hospital Medical Information Network (UMIN) Clinical Trial Registry (UMIN C000003354).

\section{Results}

Between June 2010 and January 2015, 29 patients were registered in the study. Patient characteristics are summarized in Table 1. One patient was unable to receive this experimental chemotherapy because of leukopenia

\section{Table 1. Patient characteristics.}

\begin{tabular}{|c|c|c|c|}
\hline & & & No. of patients \\
\hline Total & & & 29 \\
\hline \multirow[t]{2}{*}{ Age, years } & Median & & 64 \\
\hline & Range & & $41-71$ \\
\hline \multirow[t]{2}{*}{ Gender } & Male & & 6 \\
\hline & Female & & 23 \\
\hline Performance status & & 0 & 17 \\
\hline (ECOG) & & 1 & 12 \\
\hline Smoker & & & 12 \\
\hline \multirow[t]{2}{*}{ Clinical stage } & & IV & 27 \\
\hline & & Postoperative recurrence & 2 \\
\hline \multirow[t]{2}{*}{ Histology } & & Adenocarcinoma & 28 \\
\hline & & Non-small cell carcinoma & 1 \\
\hline \multirow[t]{3}{*}{ EGFR mutation } & & 18 & 1 \\
\hline & & 19 & 14 \\
\hline & & 21 & 14 \\
\hline Brain meta & & & 8 \\
\hline
\end{tabular}


$\leq 3000 / \mu \mathrm{L}$ just before the start of treatment. The other 28 patients were assessed for response, toxicities and survival. Induction chemotherapy was delivered as shown in Table 2. Twenty-one patients (75.0\%) were able to receive 4 cycles of $\mathrm{Cb}$ and Pem combination chemotherapy. Two patients dropped out after the first cycle of induction chemotherapy: one with grade 3 SGOT and SGPT elevation, and one with grade 3 thrombosis in the lower limbs. Induction chemotherapy was stopped after 2 cycles in 3 patients: 2 showing no tumor regression, and one with grade 4 thrombocytopenia. Two patients dropped out after 3 cycles of induction chemotherapy because of grade 3 nausea. Treatment-related toxicities during the induction chemotherapy are listed in Table 3 . One patient developed grade 4 thrombocytopenia requiring transfusion. Among non-hematological toxicities,

Table 2. Delivery of chemotherapy.

\begin{tabular}{|c|c|c|}
\hline $\mathrm{Cb}+\mathrm{Pem}$ & No. of cycles & No. of patients \\
\hline & 1 & 2 \\
\hline & 2 & 3 \\
\hline & 3 & 2 \\
\hline & 4 & 21 \\
\hline \multirow[t]{3}{*}{ Gef maintenance } & & Months \\
\hline & Median & 12.0 \\
\hline & Range & $1.0+-39.7+$ \\
\hline
\end{tabular}

Table 3. Toxicities in $\mathrm{Cb}+$ Pem combination chemotherapy.

\begin{tabular}{|c|c|c|c|c|c|c|}
\hline & \multicolumn{5}{|c|}{ Grade (NCI-CTC ver.3) } & \multirow[b]{2}{*}{$\%$ gr. 3,4} \\
\hline & 0 & 1 & 2 & 3 & 4 & \\
\hline Hemoglobin & 0 & 11 & 11 & 6 & 0 & 21.4 \\
\hline Leukocytes & 7 & 6 & 12 & 13 & 0 & 46.4 \\
\hline Neutrophils & 2 & 5 & 9 & 11 & 1 & 42.9 \\
\hline Platelets & 2 & 10 & 9 & 6 & 1 & 25.0 \\
\hline Bilirubin & 22 & 5 & 1 & 0 & 0 & - \\
\hline Creatinine & 27 & 1 & 0 & 0 & 0 & - \\
\hline SGOT & 6 & 15 & 4 & 3 & 0 & 10.7 \\
\hline SGPT & 12 & 9 & 4 & 3 & 0 & 10.7 \\
\hline Hypertension & 27 & 1 & 0 & 0 & 0 & - \\
\hline Fatigue & 1 & 18 & 8 & 1 & 0 & 3.6 \\
\hline Fever & 22 & 6 & 0 & 0 & 0 & - \\
\hline Alopecia & 26 & 2 & 0 & 0 & 0 & - \\
\hline Rash/desquation & 25 & 3 & 0 & 0 & 0 & - \\
\hline Anorexia & 23 & 4 & 1 & 0 & 0 & - \\
\hline Constipation & 21 & 7 & 0 & 0 & 0 & - \\
\hline Diahhea & 27 & 1 & 0 & 0 & 0 & - \\
\hline Gastritis & 27 & 1 & 0 & 0 & 0 & - \\
\hline Stomatitis & 26 & 1 & 1 & 0 & 0 & - \\
\hline Nausea-vomiting & 4 & 16 & 4 & 4 & 0 & 14.3 \\
\hline Taste alterration & 27 & 1 & 0 & 0 & 0 & - \\
\hline Febrile neutropenia & 28 & 0 & 0 & 0 & 0 & - \\
\hline Syncope & 27 & 0 & 0 & 1 & 0 & 3.6 \\
\hline Pneumonitis & 28 & 0 & 0 & 0 & 0 & - \\
\hline Thrombosis & 27 & 0 & 0 & 1 & 0 & 3.6 \\
\hline
\end{tabular}


grade 3 SGOT and SGPT elevation, fatigue, nausea and vomiting, syncope, and thrombosis were observed. Other non-hematological toxicities were mild and there was no febrile neutropenia. The outcome of the $\mathrm{Cb}$ and Pem regimen in the 28 patients was PR in 16, SD in 11 and PD in one, with an overall response rate of $57.1 \%$.

One responder underwent surgical resection and other 27 patients received sequential Gef treatment. The median duration of sequential Gef treatment was 12.0 months (range: 1.0+ to 39.7+ months). Eight patients who did not respond to CbPem achieved PR with Gef treatment, and the overall response rate for $\mathrm{Cb}$ and Pem followed by Gef was $85.7 \%$. Treatment-related toxicities during Gef treatment are listed in Table 4 . There were no grade 4 hematological toxicities. Non-hematological toxicities were almost mild.

Sixteen patients dropped out study mainly because of PD and received second line treatment such as erlotinib in 6, carboplatin-based chemotherapy in 5, docetaxel-based chemotherapy in 2 and others in 3 patients.

The progression-free and overall survival curves are shown in Figure 1, although these survival data are incomplete. Nine patients died during the follow-up period, and 12 of the 19 survivors had no tumor recurrence. The median progression-free time was 19.1 months (range 3.0+ to $44.1+$ months). The overall survival curve did not reach $50 \%$ and the median survival time was not determined (median 36.9+ months). Among the 21 patients who were followed up for more than 2 years, 14 survived for this period (Figure 2).

Table 4. Toxicities in gefitinib treatment.

\begin{tabular}{|c|c|c|c|c|c|c|}
\hline & \multicolumn{5}{|c|}{ Grade (NCI-CTC ver.3) } & \multirow[b]{2}{*}{$\%$ gr. 3,4} \\
\hline & 0 & 1 & 2 & 3 & 4 & \\
\hline Hemoglobin & 2 & 19 & 5 & 1 & 0 & 3.7 \\
\hline Leukocytes & 21 & 4 & 2 & 0 & 0 & - \\
\hline Neutrophils & 19 & 5 & 2 & 1 & 0 & 3.7 \\
\hline Platelets & 24 & 3 & 0 & 0 & 0 & - \\
\hline Bilirubin & 27 & 0 & 0 & 0 & 0 & - \\
\hline Creatinine & 27 & 0 & 0 & 0 & 0 & - \\
\hline SGOT & 7 & 11 & 7 & 2 & 0 & 7.4 \\
\hline SGPT & 11 & 7 & 4 & 5 & 0 & 18.5 \\
\hline Hypertension & 26 & 1 & 0 & 0 & 0 & - \\
\hline Fatigue & 9 & 16 & 2 & 0 & 0 & - \\
\hline Dry skin & 20 & 7 & 0 & 1 & 0 & 3.7 \\
\hline Nail change & 25 & 2 & 0 & 0 & 0 & - \\
\hline Pruritis & 18 & 9 & 0 & 0 & 0 & - \\
\hline Rash & 18 & 9 & 0 & 0 & 0 & - \\
\hline Acne & 19 & 7 & 1 & 0 & 0 & - \\
\hline Constipation & 20 & 7 & 0 & 0 & 0 & - \\
\hline Diahhea & 20 & 7 & 0 & 0 & 0 & - \\
\hline Gastritis & 26 & 1 & 0 & 0 & 0 & - \\
\hline Stomatitis & 24 & 3 & 0 & 0 & 0 & - \\
\hline Nausea-vomiting & 26 & 1 & 0 & 0 & 0 & - \\
\hline Febrile neutropenia & 27 & 0 & 0 & 0 & 0 & - \\
\hline Pneumonitis & 26 & 0 & 1 & 0 & 0 & - \\
\hline Cystitis & 26 & 1 & 0 & 0 & 0 & - \\
\hline Headache & 26 & 1 & 0 & 0 & 0 & - \\
\hline
\end{tabular}




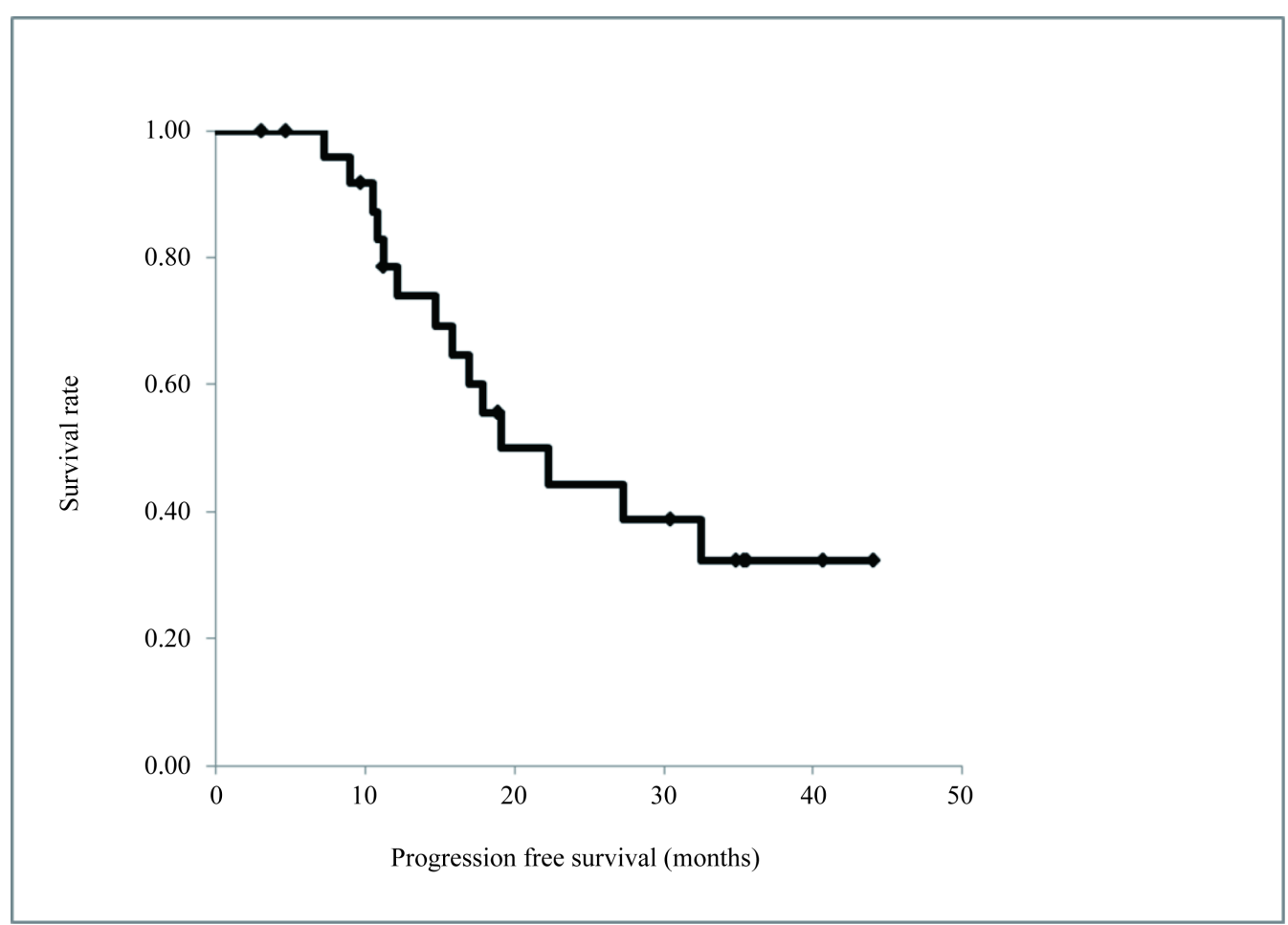

Figure 1. Progression free survival curve constructed by the Kaplan-Meier method. Twelve of the 19 survivors had no tumor recurrence. The median progression-free time was 19.1 months (range $3.0+$ to $44.1+$ months).

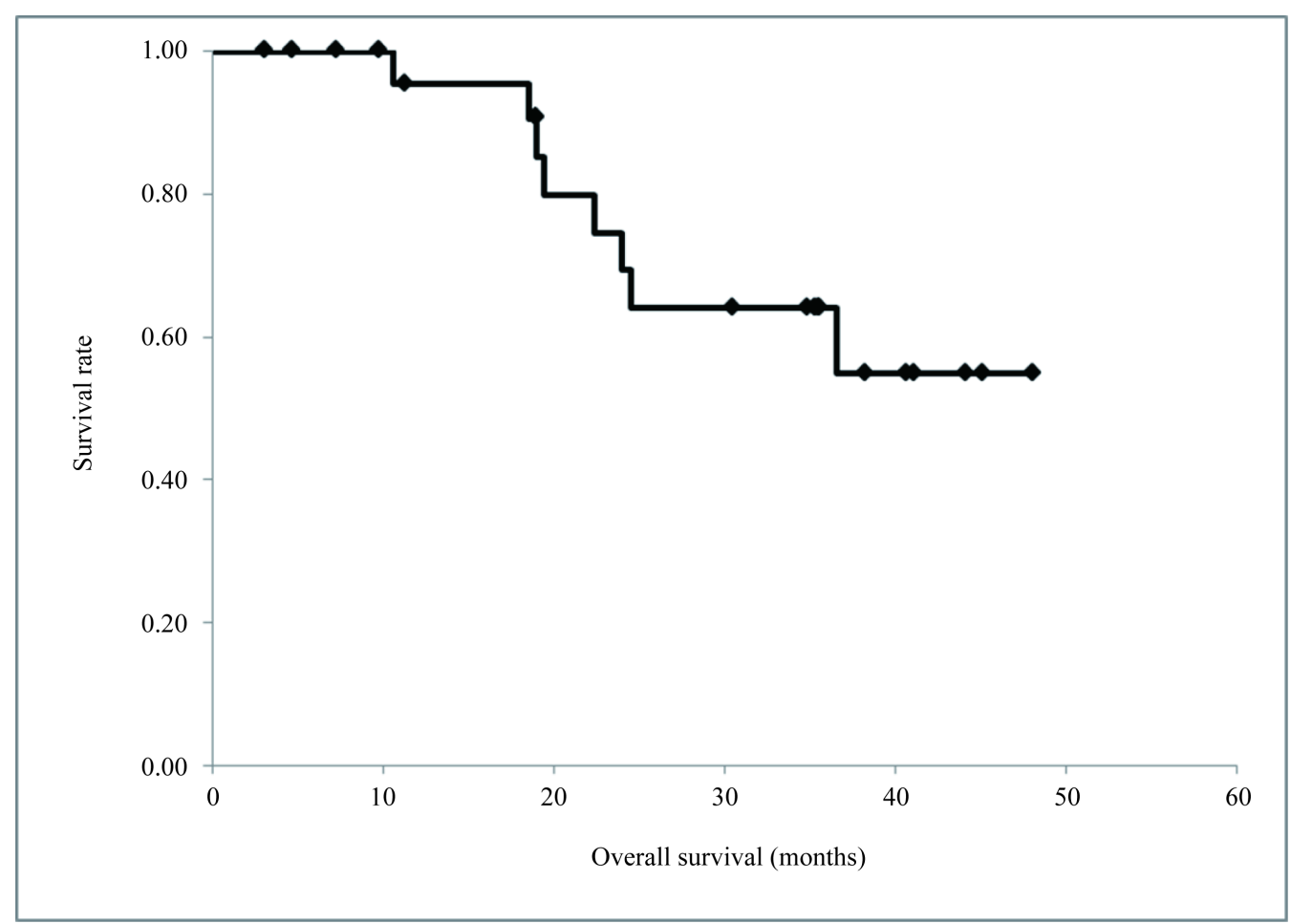

Figure 2. Overall survival curve constructed by the Kaplan-Meier method. The overall survival curve did not reach $50 \%$ and the median survival time was not determined (median 36.9+ months). Among the 21 patients who were followed up for more than 2 years, 14 survived for this period. 


\section{Discussion}

The current standard treatment for patients with NSCLC harboring sensitive EGFR mutation is EGFR-TKI monotherapy. Many clinicians have considered that not only EGFR-TKI but also cytotoxic drugs are necessary for these patients in order to improve survival. In fact, a phase III study comparing Gef with $\mathrm{Cb}$ and paclitaxel for chemo-naïve NSCLC with sensitive EGFR gene mutation found that about $10 \%$ of patients who did not receive platinum agents died within 6 months, despite the fact that most patients who received $\mathrm{Cb}$ and paclitaxel as first-line treatment were able to survive for 6 months or more. The same study also showed that patients who received EGFR-TKI, platinum agents, and Pem or docetaxel achieved significantly better overall survival than patients who received EGFR-TKI, platinum agents, but neither Pem nor docetaxel in the final analysis [19]. These data strongly support our treatment strategy using the $\mathrm{Cb}$, Pem and Gef combination. In the present study, $\mathrm{Cb}$ and Pem followed by Gef showed extremely high activity against NSCLC harboring EGFR mutation, with a response rate of $85.7 \%$. This activity was similar to that achieved with the same regimen in a recently published randomized phase II study in Japan [20]. Fourteen of 21 patients who were registered to this study for 2 years or more were able to survive for at least this period. Thus, two thirds of the studied patients survived for 2 years or more on the present combination chemotherapy. These results are more favorable than those of phase III studies of Gef monotherapy in Japan.

Twenty-one patients received 4 full cycles of the $\mathrm{Cb}$ and Pem regimen in the present study, being comparable to a phase III study of $\mathrm{Cb}$ and Pem relative to $\mathrm{Cb}$ and gemcitabine [16]. In two phase III trials conducted in Japan, about one third to half of all patients treated with Gef as first-line chemotherapy continued to receive Gef beyond the PD stage because of anxiety about chemotherapy-related cytotoxicity. Although platinum-based chemotherapies modestly improve survival and palliate some tumor-related symptoms in patients with locally advanced metastatic NSCLC, the chemotherapy-related adverse effects sometimes outweigh the benefits. Consequently, a practical short-term goal is to identify new regimens that would maintain the same level of efficacy as cisplatin-based combinations while offering a better toxicity profile. The present small phase II study demonstrated encouraging results for the $\mathrm{Cb}$ and Pem regimen. The incidence of serious hematologic and non-hematologic toxicities was similar to that in a randomized phase II study of the same treatment schedule conducted in Japan [20], which was a very low incidence in comparison with other platinum-based chemotherapies [1] [21]. Thus, the regimen is considered to be acceptable for patients who are concerned about the cytotoxicity of anti-cancer drugs.

In the present study, the median period until disease progression in patients receiving sequential treatment with Gef was 12.0 months, which was longer than the periods of 9.2 and 10.8 months for Gef monotherapy in patients with EGFR mutation in randomized studies conducted in Japan [9] [10]. Moreover, sequential Gef treatment resulted in tumor regression in 8 of 12 patients (66.7\%) who did not respond to $\mathrm{Cb}$ and Pem treatment. This response rate is equal to the activity reported for Gef alone against lung cancer harboring EGFR mutation in large-scale studies, and a response rate as high as $88.7 \%$ for the three-drug combination used in the present study. These data suggest that the anti-tumor mechanism of $\mathrm{Cb}$ and Pem differs from that of Gef.

Unfortunately, accrual of patients for this study was slow and we decided to stop the study at the first stage. A phase II study requiring 50 - 60 patients is considered difficult to perform at a single institution. The safety of the present $\mathrm{Cb}$ and Pem combination followed by Gef treatment would be sufficiently acceptable for patients who anticipate several types of toxicity induced by anti-cancer drugs, but a comparative study will be required to determine whether the present treatment could become a gold standard for patients with NSCLC harboring sensitive EGFR mutation. A phase III study has already been initiated to compare $\mathrm{Cb}$ and Pem combination chemotherapy plus Gef with standard Gef monotherapy in the setting of EGFR mutation in Japanese patients.

\section{Conclusion}

In conclusion, $\mathrm{Cb}$ and Pem followed by Gef maintenance are likely feasible and recommended for further evaluation for patients with metastatic NSCLC harboring sensitive EGFR mutation.

\section{Acknowledgements}

We thank all of the participating patients, their families, and the site investigators. The authors are also grateful to Dr. Shigeki Motomura, Dr. Makoto Ueno and Dr. Hiroaki Okamoto for assistance as the Safety Monitoring 
Committee. This work was supported in part by the Kanagawa Health Foundation and the Kanagawa Prefectural Hospitals Cancer Research Fund.

\section{References}

[1] Schiller, J.H., Harrington, D., Belani, C.P., Langer, C., Sandler, A., Krook, J., Zhu, J. and Johnson, D.H. (2002) Eastern Cooperative Oncology Group. Comparison of Four Chemotherapy Regimens for Advanced Non-Small-Cell Lung Cancer. New England Journal of Medicine, 346, 92-98. http://dx.doi.org/10.1056/NEJMoa011954

[2] Sandler, A., Gray, R., Perry, M.C., Brahmer, J., Schiller, J.H., Dowlati, A., Lilenbaum, R. and Johnson, D.H. (2006) Paclitaxel-Carboplatin Alone or with Bevacizumab for Non-Small-Cell Lung Cancer. New England Journal of Medicine, 355, 2542-2550. http://dx.doi.org/10.1056/NEJMoa061884

[3] Fukuoka, M., Yano, S., Giaccone, G., Tamura, T., Nakagawa, K., Douillard, J.Y., Nishiwaki, Y., Vansteenkiste, J., Kudoh, S., Rischin, D., Eek, R., Horai, T., Noda, K., Takata, I., Smit, E., Averbuch, S., Macleod, A., Feyereislova, A., Dong, R.P. and Baselga, J. (2003) Multi-Institutional Randomized Phase II Trial of Gefitinib for Previously Treated Patients with Advanced Non-Small-Cell Lung Cancer (The IDEAL 1 Trial). Journal of Clinical Oncology, 21, 22372246. http://dx.doi.org/10.1200/JCO.2003.10.038

[4] Kris, M.G., Natale, R.B., Herbst, R.S., Lynch Jr, T.J., Prager, D., Belani, C.P., Schiller, J.H., Kelly, K., Spiridonidis, H., Sandler, A., Albain, K.S., Cella, D., Wolf, M.K., Averbuch, S.D., Ochs, J.J. and Kay, A.C. (2003) Efficacy of Gefitinib, an Inhibitor of the Epidermal Growth Factor Receptor Tyrosine Kinase, in Symptomatic Patients with Non-Small Cell Lung Cancer: A Randomized Trial. JAMA, 290, 2149-2158. http://dx.doi.org/10.1001/jama.290.16.2149

[5] Miller, V.A., Kris, M.G., Shah, N., Patel, J., Azzoli, C., Gomez, J., Krug, L.M., Pao, W., Rizvi, N., Pizzo, B., Tyson, L., Venkatraman, E., Ben-Porat, L., Memoli, N., Zakowski, M., Rusch, V. and Heelan, R.T. (2004) Bronchioloalveolar Pathologic Subtype and Smoking History Predict Sensitivity to Gefitinib in Advanced Non-Small-Cell Lung Cancer. Journal of Clinical Oncology, 22, 1103-1109. http://dx.doi.org/10.1200/JCO.2004.08.158

[6] Lynch, T.J., Bell, D.W., Sordella, R., Gurubhagavatula, S., Okimoto, R.A., Brannigan, B.W., Harris, P.L., Haserla,t S.M., Supko, J.G., Haluska, F.G., Louis, D.N., Christiani, D.C., Settleman, J. and Haber, D.A. (2004) Activating Mutations in the Epidermal Growth Factor Receptor Underlying Responsiveness of Non-Small-Cell Lung Cancer to Gefitinib. New England Journal of Medicine, 350, 2129-2139. http://dx.doi.org/10.1056/NEJMoa040938

[7] Paez, J.G., Jänne, P.A., Lee, J.C., Tracy, S., Greulich, H., Gabriel, S., Herman, P., Kaye, F.J., Lindeman, N., Boggon, T.J., Naoki, K., Sasaki, H., Fujii, Y., Eck, M.J., Sellers, W.R., Johnson, B.E. and Meyerson, M. (2004) EGFR Mutations in Lung Cancer: Correlation with Clinical Response to Gefitinib Therapy. Science, 304, 1497-1500. http://dx.doi.org/10.1126/science.1099314

[8] Mok, T.S., Wu, Y.L., Thongprasert, S., Yang, C.H., Chu, D.T., Saijo, N., Sunpaweravong, P., Han, B., Margono, B., Ichinose, Y., Nishiwaki, Y., Ohe, Y., Yang, J.J., Chewaskulyong, B., Jiang, H., Duffield, E.L., Watkins, C.L., Armour, A.A. and Fukuoka, M. (2009) Gefitinib or Carboplatin-Paclitaxel in Pulmonary Adenocarcinoma. New England Journal of Medicine, 361, 947-957. http://dx.doi.org/10.1056/NEJMoa0810699

[9] Maemondo, M., Inoue, A., Kobayashi, K., Sugawara, S., Oizumi, S., Isobe, H., Gemma, A., Harada, M., Yoshizawa, H., Kinoshita, I., Fujita, Y., Okinaga, S., Hirano, H., Yoshimori, K., Harada, T., Ogura, T., Ando, M., Miyazawa, H., Tanaka, T., Saijo, Y., Hagiwara, K., Morita, S. and Nukiwa, T. (2010) North-East Japan Study Group: Gefitinib or Chemotherapy for Non-Small-Cell Lung Cancer with Mutated EGFR. New England Journal of Medicine, 362, 23802388. http://dx.doi.org/10.1056/NEJMoa0909530

[10] Mitsudomi, T., Morita, S., Yatabe, Y., Negoro, S., Okamoto, I., Tsurutani, J., Seto, T., Satouchi, M., Tada, H., Hirashima, T., Asami, K., Katakami, N., Takada, M., Yoshioka, H., Shibata, K., Kudoh, S., Shimizu, E., Saito, H., Toyooka, S., Nakagawa, K. and Fukuoka, M. (2010) West Japan Oncology Group: Gefitinib versus Cisplatin plus Docetaxel in Patients with Non-Small-Cell Lung Cancer Harbouring Mutations of the Epidermal Growth Factor Receptor (WJTOG3405): An Open Label, Randomised Phase 3 Trial. Lancet Oncology, 11, 121-128. http://dx.doi.org/10.1016/S1470-2045(09)70364-X

[11] Rosell, R., Carcereny, E., Gervais, R., Vergnenegre, A., Massuti, B., Felip, E., Palmero, R., Garcia-Gomez, R., Pallares, C., Sanchez, J.M., Porta, R., Cobo, M., Garrido, P., Longo, F., Moran, T., Insa, A., De Marinis, F., Corre, R., Bover, I., Illiano, A., Dansin, E., de Castro, J., Milella, M., Reguart, N., Altavilla, G., Jimenez, U., Provencio, M., Moreno, M.A., Terrasa, J., Muñoz-Langa, J., Valdivia, J., Isla, D., Domine, M., Molinier, O., Mazieres, J., Baize, N., Garcia-Campelo, R., Robinet, G., Rodriguez-Abreu, D., Lopez-Vivanco, G., Gebbia, V., Ferrera-Delgado, L., Bombaron, P., Bernabe, R., Bearz, A., Artal, A., Cortesi, E., Rolfo, C., Sanchez-Ronco, M., Drozdowskyj, A., Queralt, C., de Aguirre, I., Ramirez, J.L., Sanchez, J.J., Molina, M.A., Taron, M. and Paz-Ares, L., Spanish Lung Cancer Group in Collaboration with Groupe Français de Pneumo-Cancérologie and Associazione Italiana Oncologia Toracica (2012) Erlotinib versus Standard Chemotherapy as First-Line Treatment for European Patients with Advanced EGFR Mutation-Positive NonSmall-Cell Lung Cancer (EURTAC): A Multicentre, Open-Label, Randomised Phase 3 Trial. The Lancet Oncology, 13, 239-246. http://dx.doi.org/10.1016/S1470-2045(11)70393-X 
[12] Zhou, C., Wu, Y.L., Chen, G., Feng, J., Liu, X.Q., Wang, C., Zhang, S., Wang, J., Zhou, S., Ren, S., Lu, S., Zhang, L., Hu, C., Hu, C., Luo, Y., Chen, L., Ye, M., Huang, J., Zhi, X., Zhang, Y., Xiu, Q., Ma, J., Zhang, L. and You, C. (2011) Erlotinib versus Chemotherapy as First-Line Treatment for Patients with Advanced EGFR Mutation-Positive NonSmall-Cell Lung Cancer (OPTIMAL, CTONG-0802): A Multicentre, Open-Label, Randomised, Phase 3 Study. The Lancet Oncology, 12, 735-742. http://dx.doi.org/10.1016/S1470-2045(11)70184-X

[13] Scagliotti, G.V., Parikh, P., von Pawel, J., Biesma, B., Vansteenkiste, J., Manegold, C., Serwatowski, P., Gatzemeier, U., Digumarti, R., Zukin, M., Lee, J.S., Mellemgaard, A., Park, K., Patil, S., Rolski, J., Goksel, T., de Marinis, F., Simms, L., Sugarman, K.P. and Gandara, D. (2008) Phase III Study Comparing Cisplatin plus Gemcitabine with Cisplatin plus Pemetrexed in Chemotherapy-Naive Patients with Advanced-Stage Non-Small-Cell Lung Cancer. Journal of Clinical Oncology, 26, 3543-3551. http://dx.doi.org/10.1200/JCO.2007.15.0375

[14] Ardizzoni, A., Boni, L., Tiseo, M., Fossella, F.V., Schiller, J.H., Paesmans, M., Radosavljevic, D., Paccagnella, A., Zatloukal, P., Mazzanti, P., Bisset, D. and Rosell, R., CISCA (CISplatin versus CArboplatin) Meta-Analysis Group (2007) Cisplatin- versus Carboplatin-Based Chemotherapy in First-Line Treatment of Advanced Non-Small-Cell Lung Cancer: An Individual Patient Data Meta-Analysis. Journal of the National Cancer Institute, 99, 847-857. http://dx.doi.org/10.1093/jnci/djk196

[15] Jiang, J., Liang, X., Zhou, X., Huang, R. and Chu, Z. (2007) A Meta-Analysis of Randomized Controlled Trials Comparing Carboplatin-Based to Cisplatin-Based Chemotherapy in Advanced Non-Small Cell Lung Cancer. Lung Cancer, 57, 348-358. http://dx.doi.org/10.1016/j.lungcan.2007.03.014

[16] Grønberg, B.H., Bremnes, R.M., Fløtten, O., Amundsen, T., Brunsvig, P.F., Hjelde, H.H., Kaasa, S., von Plessen, C., Stornes, F., Tollåli, T., Wammer, F., Aasebø, U. and Sundstrøm, S. (2009) Phase III Study by the Norwegian Lung Cancer Study Group: Pemetrexed plus Carboplatin Compared with Gemcitabine plus Carboplatin as First-Line Chemotherapy in Advanced Non-Small-Cell Lung Cancer. Journal of Clinical Oncology, 27, 3217-3224. http://dx.doi.org/10.1200/JCO.2008.20.9114

[17] Therasse, P., Arbuck, S.G., Eisenhauer, E.A., Wanders, J., Kaplan, R.S., Rubinstein, L., Verweij, J., Van Glabbeke, M., van Oosterom, A.T., Christian, M.C. and Gwyther, S.G. (2000) New Guidelines to Evaluate the Response to Treatment in Solid Tumors. Journal of the National Cancer Institute, 92, 205-216. http://dx.doi.org/10.1093/jnci/92.3.205

[18] Simon, R. (1989) Optimal Two-Stage Designs for Phase II Clinical Trial. Controlled Clinical Trials, 10, 1-10. http://dx.doi.org/10.1016/0197-2456(89)90015-9

[19] Inoue, A., Kobayashi, K., Maemondo, M., Sugawara, S., Oizumi, S., Isobe, H., Gemma, A., Harada, M., Yoshizawa, H., Kinoshita, I., Fujita, Y., Okinaga, S., Hirano, H., Yoshimori, K., Harada, T., Saijo, Y., Hagiwara, K., Morita, S. and Nukiwa, T., North-East Japan Study Group (2013) Updated Overall Survival Results from a Randomized Phase III Trial Comparing Gefitinib with Carboplatin-Paclitaxel for Chemo-Naïve Non-Small Cell Lung Cancer with Sensitive EGFR Gene Mutations (NEJ002). Annals of Oncology, 24, 54-59. http://dx.doi.org/10.1093/annonc/mds214

[20] Sugawara, S., Oizumi, S., Minato, K., Harada, T., Inoue, A., Fujita, Y., Maemondo, M., Yoshizawa, H., Ito, K., Gemma, A., Nishitsuji, M., Harada, M., Isobe, H., Kinoshita, I., Morita, S., Kobayashi, K., Hagiwara, K., Kurihara, M. and Nukiwa, T., on behalf of North East Japan Study Group and Tokyo Cooperative Oncology Group (2015) Randomized Phase II Study of Concurrent versus Sequential Alternating Gefitinib and Chemotherapy in Previously Untreated NonSmall Cell Lung Cancer with Sensitive EGFR Mutations: NEJ005/TCOG0902. Annals of Oncology, 26, 888-894. http://dx.doi.org/10.1093/annonc/mdv063

[21] Ohe, Y., Ohashi, Y., Kubota, K., Tamura, T., Nakagawa, K., Negoro, S., Nishiwaki, Y., Saijo, N., Ariyoshi, Y. and Fukuoka, M. (2007) Randomized Phase III Study of Cisplatin plus Irinotecan versus Carboplatin plus Paclitaxel, Cisplatin plus Gemcitabine, and Cisplatin plus Vinorelbine for Advanced Non-Small-Cell Lung Cancer: Four-Arm Cooperative Study in Japan. Annals of Oncology, 18, 317-323. http://dx.doi.org/10.1093/annonc/mdl377

\section{Abbreviations}

NSCLC: non-small cell lung cancer;

Cb: carboplatin;

Pem: pemetrexed;

Gef: gefitinib;

EGFR: epidermal growth factor receptor;

TKI: tyrosine kinase inhibitors;

AUC: a target area under the curve. 